\title{
Bortezomib in Kidney Transplantation
}

\section{Rajeev Raghavan, ${ }^{1,2}$ Abdallah Jeroudi, ${ }^{1}$ Katafan Achkar, ${ }^{3,4}$ A. Osama Gaber, ${ }^{5}$ Samir J. Patel, ${ }^{6}$ and Abdul Abdellatif ${ }^{1,2}$}

${ }^{1}$ Department of Medicine, Baylor College of Medicine, Houston, TX 77030, USA

${ }^{2}$ Division of Nephrology, Baylor College of Medicine, Houston, TX 77030, USA

${ }^{3}$ Department of Medicine, The Kidney Institute and The Methodist Hospital, Houston, TX 77030, USA

${ }^{4}$ Division of Nephrology, The Kidney Institute and The Methodist Hospital, Houston, TX 77030, USA

${ }^{5}$ Department of Surgery, The Methodist Hospital, Weill Cornell University, Houston, TX 77030, USA

${ }^{6}$ Department of Pharmacy, The Methodist Hospital, Weill Cornell University, Houston, TX 77030, USA

Correspondence should be addressed to Abdul Abdellatif, abdula@bcm.edu

Received 27 July 2010; Accepted 9 September 2010

Academic Editor: H. Kreis

Copyright (c) 2010 Rajeev Raghavan et al. This is an open access article distributed under the Creative Commons Attribution License, which permits unrestricted use, distribution, and reproduction in any medium, provided the original work is properly cited.

Although current therapies for pretransplant desensitization and treatment of antibody-mediated rejection (AMR) have had some success, they do not specifically deplete plasma cells that produce antihuman leukocyte antigen (HLA) antibodies. Bortezomib, a proteasome inhibitor approved for the treatment of multiple myeloma (a plasma cell neoplasm), induces plasma cell apoptosis. In this paper we review the current body of literature regarding the use of this biological agent in the field of transplantation. Although limited experience with bortezomib may seem to show promise in the realm of transplant recipients desensitization and treatment of AMR, there is also experience that may suggest otherwise. Bortezomib's role in desensitization protocols and treatment of AMR will be defined better as more clinical data and trials become available.

\section{Introduction}

Kidney transplantation is the treatment of choice for most patients with stage five chronic kidney disease (CKD). The risk of death is less than half of that for dialysis patients regardless of the immunosuppression protocol used [1]. Furthermore, most recipients acknowledge improved quality of life. It is not surprising that the demand for donor kidneys continually outpaces the supply. The United Network for Organ Sharing (UNOS) has over 80,000 patients on the kidney transplant waiting list, many of whom are highly sensitized. Data obtained from the UNOS (2001-2008) showed that the rates of transplantation for living donor (LD) and deceased donor (DD) by panel reactive antibody (PRA) status are less than $16 \%$ per year for patients with PRAs of $10 \%$ to $80 \%$, and less than $8 \%$ for patients with PRAs more than $80 \%$. Thus, sensitized patients with any level of PRA are difficult to transplant and have longer waiting times on the transplant list [2]. Strategies for removing or decreasing preformed antibodies in these patients are termed desensitization. Literature review demonstrates 1-year allograft survival between $69 \%$ and $96 \%$ for desensitizieted patients [3].

The rejection risk for all patients in the first year post transplant is less than $12 \%$ based on the 2009 USRDS database [4]. Highly sensitized transplant recipients, regardless of the desensitization protocol used, are at increased risk for AMR. Both desensitization and AMR are managed with the similar therapeutic arsenal; however protocols are centerspecific and there are no consensus guidelines [5]. The two desensitization protocols for which clinical efficacy has been demonstrated are high-dose IVIG or low-dose IVIG with either plasmapheresis (PP) or immunoadsorption $[6,7]$. Additionally, some transplant centers may add intravenous steroids, rabbit antithymocyte globulin (rATG), or rituximab [8]. As mentioned above, these modalities are variably effective in decreasing reactive antibody levels [9-11].

There is concern that the role of plasma cells in mediating humoral rejection is not adequately addressed [9]. Since plasma cells do not express CD20, they are not depleted 


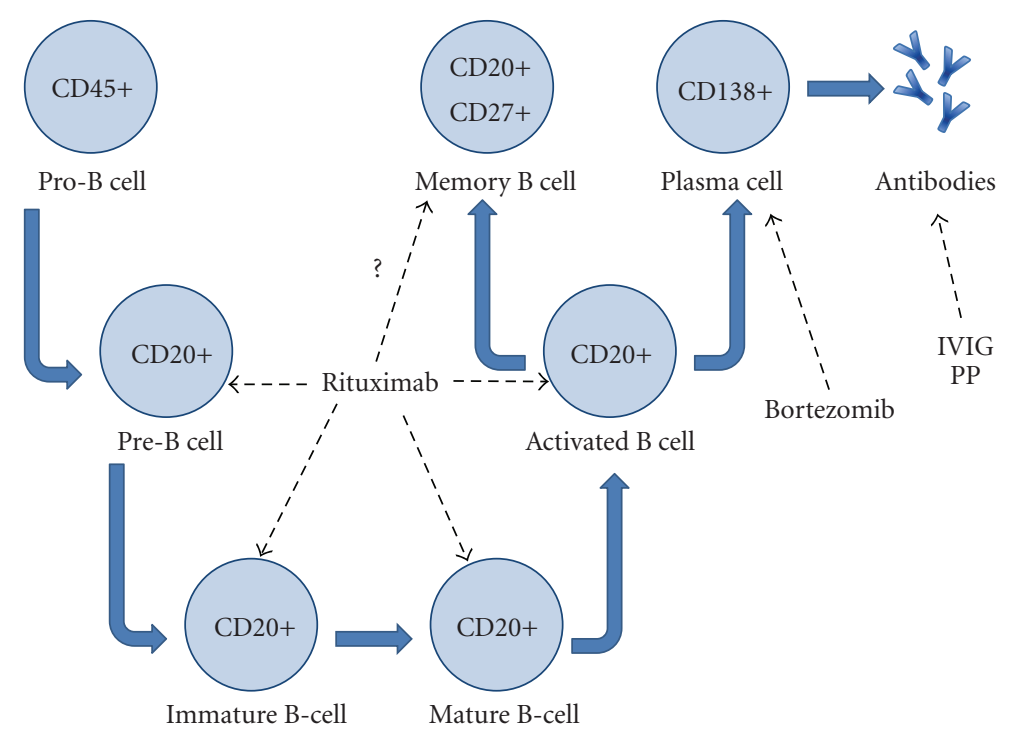

FIGURE 1: A simplified, conceptual diagram of the targets of current therapeutic modalities for pre-transplant desensitization and treatment of antibody mediated rejection. The dashed arrows indicate the sites of action for the therapeutics. Rituximab exerts its effects on CD20+ B-cell lines with absence of activity against pro-B cells and plasma cells and questionable activity against memory B cells. Bortezomib targets plasma cells which elaborate the antibodies implicated in donor-specific antibodies and antibody-mediated rejection while the antibodies produced are targeted with intravenous immunoglobulin (IVIG) and plasmapheresis (PP).

by rituximab's ability to deplete CD20 positive B-cell line members as detailed in (Figure 1). There is one variant of AMR in which over $30 \%$ of infiltrating cells are mature plasma cells, and once diagnosed graft survival is generally less than one year post diagnosis [12]. Hence, it is of importance to target this cell lineage in desensitization and AMR treatment strategies.

Reservations were expressed in the literature that plasma cells were unaffected by current desensitization protocols. The study by Ramos et al. confirmed these ruminations. The group conducted a study where the spleens of patients receiving desensitization were histologically compared to control spleens for their levels of different B-cell line members [13]. The study showed that levels of naïve $B$ cells (CD20+ and CD79+), memory B cells (CD27+), and plasma cells (CD138+) in the spleens of patients desensitized with PP and low-dose IVIG did not differ significantly from control spleens. It was also noted that despite the addition of rituximab to the PP and IVIG protocol, the amount of memory B cells and plasma cells were still comparable to controls. Combination therapy in the study (PP, low-dose IVIG, rituximab, and rATG) did show a small reduction of memory B cells, but plasma cell levels were still on par with controls. This study confirmed the reservations expressed in the literature that plasma cells were unaffected by current desensitization protocols $[9,13]$.

Bortezomib (Velcade, Millennium Pharmaceuticals, Cambridge, MA) depletes plasma cells via proteasome inhibition [8]. In 2008, investigators at the University of Cincinnati published their experience of six patients with AMR and donor-specific antibodies (DSA) elevation post transplantation who had reversal of AMR with a single cycle of bortezomib [14]. Several other transplant centers have since utilized bortezomib for treatment of AMR with varying success [14-20]. Herein, we review the current body of literature regarding using bortezomib in pretransplant desensitization and treatment of AMR.

\section{Bortezomib Biological Effect}

Bortezomib was first synthesized in 1995. After just seven years, the Food and Drug Administration (FDA) approved this drug as treatment for multiple myeloma, a plasma cell dyscrasia, which remains its only approved indication. A phase 3 multicenter trial published in the New England Journal of Medicine in 2008 demonstrated marked improvement in outcomes for newly diagnosed myeloma patients who received bortezomib in addition to the treatment standard of melphalan and prednisone. This 682-patient randomized trial demonstrated the superiority, along with safety and efficacy of Bortezomib. Now this drug is first-line treatment in patients with newly diagnosed myeloma who cannot receive immediate autologous stem cell transplantation [21]. The drug has been used off label in the transplant setting since 2005 both to reduce DSAs in highly sensitized patients and as an adjunct therapy for AMR.

Bortezomib $\left(\mathrm{C}_{19} \mathrm{H}_{25} \mathrm{BN}_{4} \mathrm{O}_{4}\right)$ has a central boron atom which binds the catalytic site of the $26 \mathrm{~S}$ proteasome with high affinity and specificity. Present in all cells, the proteasome degrades ubiquitinylated, abnormal, and misfolded proteins; thus regulating protein expression and function [22]. Simply put, proteasome inhibition during mitosis inhibits the degradation of cell-cycle regulatory proteins resulting in cell-cycle death via apoptosis. One such regulatory protein is NFkB, which has an important role in controlling cell cycle progression, loading of Class I MHC molecules, cell 
adhesion, and activation of cytokines [23]. This molecule is inhibited by transcription factor IkB. Bortezomib's interference with these two molecules leads to the accumulation and aggregation of unfolded proteins and eventual plasma cell apoptosis.

Both in vitro and in vivo (murine and human) studies have noted that this drug has a propensity to cause apoptosis of CD138+ plasma cells $[16,24]$. Bortezomib also exerts numerous indirect effects on circulating $\mathrm{B}$ cells and $\mathrm{T}_{\mathrm{H}}$ cells; for example, it may lead to blockade of T-cell cycling leading to apoptosis of $\mathrm{T}_{\mathrm{H}}$ cells and reduction of bone marrow interleukin-6 can decrease B-cells numbers [21].

\section{Bortezomib Pharmacokinetics, Pharmacodynamics, and Side Effects}

The pharmacokinetics of bortezomib can be characterized by rapid and wide distribution, a prolonged elimination half life, and hepatic cytochrome P-450 (CYP) isoenzyme metabolism [25]. After a rapid distribution half life of approximately 10 minutes, peak plasma bortezomib concentrations range 60 to $120 \mathrm{ng} / \mathrm{mL}$ following repeated doses of 1 to $1.3 \mathrm{mg} / \mathrm{m}^{2}$. Total body clearance decreases from 102 to $112 \mathrm{~L} / \mathrm{h}$ after the first dose and from 15 to $32 \mathrm{~L} / \mathrm{h}$ following repeated doses [26]. Subsequent elimination half-life ranges from 40 to 190 hours. A high volume of distribution (500 to $1800 \mathrm{~L} / \mathrm{m}^{2}$ ) in patients with multiple myeloma is suggestive of extensive distribution to peripheral tissues. In vitro studies indicate bortezomib metabolism to occur primarily via hepatic oxidation by CYP3A4, CYP2C19, CPY1A2, and to a lesser extent CYP2D6 and CYP2C9, to inactive metabolites. While inhibitors and inducers of these isoenzymes are commonly seen especially in organ transplant populations, clinically significant interactions with bortezomib and enzyme inducers have not been reported. Concomitant administration of ketoconazole has been shown to increase systemic bortezomib exposure by 35\% with corresponding increased proteasome inhibitory activity, although side effects were similar to those not receiving ketoconazole [27]. On the other hand, ascorbic acid (Vitamin C) has been shown to interfere with bortezomib's proteasome inhibitory activity through alternative mechanisms [28]. The pharmacodynamic profile of bortezomib provided a basis for its current recommended dosing regimen. Following intravenous administration, maximum percent inhibition of $20 \mathrm{~S}$ proteasome is observed after 5 minutes, reaching a mean of $70-84 \%$ inhibition [26]. With decreases in drug concentration, 20S proteasome inhibition is reversed with mean inhibition declining to $22-48 \%$ at 48 hours and returning to baseline at 72 hours post administration. Pharmacodynamic properties were similar between 1.0 and $1.3 \mathrm{mg} / \mathrm{m}^{2}$ dose regimens [26]. Adverse effects are reported in Phase II and Phase III studies from multiple myeloma and mantle cell lymphoma populations. The main adverse effect of this drug is neurotoxicity which manifests as a dose-related peripheral sensory neuropathy that may occur in about $30 \%$ of treated patients. This neuropathy can often be severe but is reversible with discontinuation of the drug. Severe events (National Cancer Institute Common
Toxicity Criteria grade 3 event) also noted with bortezomib therapy include thrombocytopenia (28\%) and neutropenia (11\%) which are usually managed with standard approaches. Thrombocytopenia due to bortezomib has been observed to occur in patients primarily with low baseline platelet levels and resolves upon drug discontinuation. Other commonly reported side effects include nausea (55\%), diarrhea (44\%), and fatigue (12\%); the gastrointestinal disturbances are usually mild and managed easily with standard approaches [29]. In the largest series of kidney transplant recipients to date, Walsh et al. report a similar pattern of adverse effects, including low-grade gastrointestinal side effects, mild to moderate anemia, neutropenia, and thrombocytopenia, and primarily mild cases of peripheral neuropathy in patients undergoing treatment for desensitization and humoral rejection [30].

Dosing of bortezomib is similar regardless of the route of application, it does not require renal or hepatic dosing adjustments, and the drug is no longer detectable within 30 minutes of injection [22].

\section{Bortezomib Use in Kidney Transplantation}

To our knowledge, this drug has never consistently been used in nonkidney transplant protocols. There are several published case reports and case series detailing bortezomib's application in kidney transplantation. Many centers now use velcade-based protocols for highly sensitized patients.

4.1. Bortezomib in Desensitization Protocols. Table 1 lists the published data of this drug's use in kidney transplantation. The first published data is from University of Cincinnati by Idica et al. [17] in 2008. Thirteen highly sensitized patients received this drug and all had reduction in the normalized mean fluorescent units (MFI) of the donorspecific antibodies; ten of whom (77\%) had significant decrease in DSA.

Trivedi et al. reported on 11 patients with a posttransplant anti-HLA antibody titer greater than $1000 \mathrm{MFI}$, but without acute rejection. The use of bortezomib with plasmapheresis was successful in decreasing antibody levels to under $1000 \mathrm{MFI}$ within a median time of 24 days from treatment initiation in all but two patients [15]. Both of these two patients had a peak MFI greater than 10,000. Overall the study suggests that bortezomib can be used to decrease DSA levels with minimal toxicity [15]. Four of 11 patients had reappearance of anti-HLA antibodies despite initial effective reduction with one cycle of bortezomib. The authors suggested that certain patients may need more than one cycle of treatment to decrease DSA levels. With clinically stable patients, the study's findings neither argues for nor against bortezomib's ability to affect the clinical course of graft rejection, but the study does point to the possible role that bortezomib can play in decreasing DSA levels that are implicated in AMR.

In the case series by Wahrmann et al., the group used two cycles of bortezomib for pre-transplant desensitization for two highly sensitized kidney recipients [18]. The first cycle of bortezomib was given alone followed by a cycle of 
TABLE 1: Clinical characteristics and outcomes of published desensitization/rejection protocols using Bortezomib as combination or solo therapy.

\begin{tabular}{|c|c|c|c|c|c|c|}
\hline $\begin{array}{l}\text { Author } \\
\text { (reference) }\end{array}$ & Center & $\mathrm{N}$ & Indication $^{1}$ & Complete therapy & Results Summary & Conclusions \\
\hline $\begin{array}{l}\text { Wahrmann et al. } \\
2010[18]\end{array}$ & $\begin{array}{l}\text { Vienna, } \\
\text { Austria }\end{array}$ & 2 & DS & $\begin{array}{l}\text { (i) } 2 \text { cycles bortezomib at } \\
\text { intervals of } 3 \text { - and } \\
\text { 4-months, both given with } \\
\text { steroids }\end{array}$ & $\begin{array}{l}\text { (i) cPRA mildly decreased in both } \\
\text { patients } \\
\text { (ii) Overall, no significant effect on the } \\
\text { levels of antigen-specific IgG or ABO } \\
\text { blood group antibodies }\end{array}$ & - \\
\hline $\begin{array}{l}\text { Walsh et al. } \\
2010[19]\end{array}$ & $\begin{array}{l}\text { Cincinnati } \\
\text { Ohio, USA }\end{array}$ & 2 & AMR & $\begin{array}{l}\text { (i) } 1 \text { cycle bortezomib } \\
\text { (ii) ongoing } \\
\text { plasmapheresis, rituximab, } \\
\text { intravenous steroids } \\
\text { (iii) pheresis done at least } \\
72 \text { hours post-bortezomib }\end{array}$ & $\begin{array}{l}\text { (i) Immediate significant reduction of } \\
\text { DSA } \\
\text { (ii) Good allograft function at 5- and } \\
\text { 6-months follow-up } \\
\text { (iii) One patient had re-elevation of } \\
\text { DSA which responded to a second } \\
\text { course of treatment }\end{array}$ & + \\
\hline $\begin{array}{l}\text { Sberro-Soussan } \\
\text { et al. } 2010[20]\end{array}$ & Paris, France & 4 & $\mathrm{AMR}^{4}$ & $\begin{array}{l}\text { (i) } 1 \text { cycle bortezomib (solo } \\
\text { therapy) }\end{array}$ & $\begin{array}{l}\text { (i) No effect on anti-HLA antibodies } \\
\text { within } 40 \text { subsequent days, and at } 150 \\
\text { days follow-up. }\end{array}$ & - \\
\hline $\begin{array}{l}\text { Raghavan et al. } \\
2009[31]\end{array}$ & $\begin{array}{l}\text { Houston, TX, } \\
\text { USA }\end{array}$ & 1 & DS & $\begin{array}{l}\text { (i) } 4 \text { cycles bortezomib, one } \\
\text { dose rituximab, daily } \\
\text { mycophenolate }\end{array}$ & $\begin{array}{l}\text { (i) Reduced PRA }(55 \% \rightarrow 30 \%) \text { and } \\
\text { significant reduction of class I } \\
\text { antibodies } \\
\text { (ii) Successful transplant with good } \\
\text { allograft function at 6-months }\end{array}$ & + \\
\hline Everly 2009 [14] & $\begin{array}{l}\text { Cincinnati } \\
\text { Ohio, USA }\end{array}$ & 5 & AMR & $\begin{array}{l}\text { (i) } 1 \text { cycle bortezomib post } \\
\text { treatment with "other" } \\
\text { antihumoral therapies }\end{array}$ & $\begin{array}{l}\text { (i) Median follow-up of } 6.9 \text { months. } \\
\text { All patients had } 50 \% \text { reduction of DSA } \\
\text { in } 2-4 \text { weeks. } \\
\text { (ii) side effects in } 4 \text { of } 5 \text { patients } \\
\text { (gastrointestinal, hematologic) })^{3}\end{array}$ & + \\
\hline $\begin{array}{l}\text { Trivedi et al. } \\
2009[15]\end{array}$ & $\begin{array}{l}\text { Ahmedabad, } \\
\text { Gujarat, India }\end{array}$ & 11 & $\begin{array}{l}\text { Elevated } \\
\text { DSA with } \\
\text { MFI > } 1000\end{array}$ & $\begin{array}{l}\text { (i) } 1 \text { cycle bortezomib } \\
\text { followed by } 2-4 \text { treatments } \\
\text { plasmapheresis and steroids } \\
\text { (ii) } 6 \text { of } 11 \text { patients received } \\
\text { one dose rituximab }\end{array}$ & $\begin{array}{l}\text { (i) Follow-up at least } 80 \text { days post } \\
\text { treatment. All patients had reduction } \\
\text { in MFI within } 4 \text { weeks. } \\
\text { (ii) } 7 \text { of } 11 \text { patients had reappearance } \\
\text { of anti-HLA antibodies }\end{array}$ & $+1-$ \\
\hline $\begin{array}{l}\text { Perry et al. } 2009 \\
{[16]}\end{array}$ & $\begin{array}{l}\text { Rochester, } \\
\text { MN, USA }\end{array}$ & 2 & AMR & $\begin{array}{l}\text { (i) } 1 \text { cycle bortezomib, daily } \\
\text { plasmapheresis and IVIG }\end{array}$ & $\begin{array}{l}\text { (i) Resolution of Rejection Peak MFI } \\
13 \mathrm{k} \text { and } 14 \mathrm{k}^{2} \text { At } 1 \text {-year follow-up: MFI } \\
\text { zero at and serum creatinine } 0.6 \text { and } \\
1.3 \mathrm{mg} / \mathrm{dl}\end{array}$ & + \\
\hline $\begin{array}{l}\text { Idica et al. } 2008 \\
\text { [17] }\end{array}$ & ?? & 13 & DS & $\begin{array}{l}\text { (i) Details not apparent } \\
\text { from article }\end{array}$ & $\begin{array}{l}\text { (i) } 10 \text { of } 13 \text { had significant decrease } \\
\text { (reversal) of DSA } \\
\text { (ii) } 100 \% \text { had reduced MFI of } \\
\text { antibodies }\end{array}$ & + \\
\hline
\end{tabular}

${ }^{1}$ DS: Desensitization, AMR = Antibody Mediated Rejection, DSA: Donor Specific Antibodies (elevated antibodies, but no clinical rejection). ${ }^{2}$ MFI: Mean Fluorescence Index. ${ }^{3}$ Side effects mentioned include thrombocytopenia and gastrointestinal toxicities. ${ }^{4}$ Patients had subclinical antibody mediated injuries with persistent DSA; hence it was acceptable to use bortezomib as solo therapy.

bortezomib with dexamethasone as dexamethasone has been shown to enhance treatment efficacy in multiple myeloma patients. In the two patients, PRA decreased from $87 \%$ to $80 \%$ in patient 1 and $37 \%$ to $13 \%$ in patient 2. Despite the mild decrease in PRA levels, bortezomib therapy led to more than $50 \%$ decrease in the levels of anti-HLA antibodies triggering C4d deposition on single antigen Luminex beads as measured in MFI after 6 months of followup. This suggests that bortezomib may have a role in decreasing complement fixation especially as C4d is one of the histological markers leading to the diagnosis of AMR [18]. Yet, bortezomib's mild effect on PRA for pre-transplant desensitization may suggest the need for adjunct modalities that target antibodies such as
PP and IVIG as well as further exploration of bortezomib in transplant desensitization.

4.2. Bortezomib in Rejection Protocols. In the first study to use bortezomib as an antirejection modality, 6 kidney transplant recipients with AMR and acute cellular rejection (ACR) refractory to plasmapheresis, IVIG, and/or rATG, and/or rituximab were treated with bortezomib [14]. Bortezomib therapy led to prompt rejection reversal (within days to weeks) and in all the cases, there was improved renal function and reduction in DSA levels. Recurrent rejection episodes in 2 patients were suppressed for up to 5 months; furthermore, the anti-HLA antibody with the highest levels 
(immunodominant DSA) were decreased by more than $50 \%$ within 14 days and remained suppressed for up to 5 months [14]. As the first positive study of incorporating bortezomib as a suppressor of DSA in the treatment of AMR, others groups have emulated this strategy.

Perry et al. analyzed the effects of rATG, IVIG, rituximab, and bortezomib on enriched populations of bone marrow derived plasma cells and indicated that only bortezomib was successful in causing plasma cell apoptosis and completely blocking anti-HLA IgG secretion against all specificities in vitro compared to controls [16]. In comparing the bone marrow of 2 positive cross-match kidney recipients at the time of AMR and at 1 week after treatment with bortezomib for AMR, in vivo data showed a decrease in the percentage of bone marrow plasma cells, a decrease in antibody production (including DSA), and a decrease in the number of plasma cell allospecificities in the bone marrow aspirates obtained after bortezomib treatment. With resolution of AMR and normal kidney function at one year post transplant, the study suggests that bortezomib can target plasma cells implicated in AMR [16].

In the study by Walsh et al., two patients undergoing acute AMR with high DSA and positive Cd4 staining on biopsy two weeks after kidney transplantation were treated with a multiday regimen consisting of PP paired with methylprednisolone and bortezomib along with a single dose of rituximab [19]. The theoretical rationale behind this protocol was that bortezomib would target plasma cells, rituximab would target plasma cell production from the pool of memory B-cells, and plasmapheresis would remove antibody levels creating a demand for increased antibody production to potentiate the effect of bortezomib's proteasome inhibition. In addition, plasmapheresis was used to remove pre-existing antibodies that may have been circulating for weeks and thus measure antibody levels that would correlate with the magnitude of the antibody producing plasma cell population. By nearly 14 days after treatment, DSA levels had dropped significantly as well as repeat biopsy showed faint peritubular capillary C4d labeling and decreased glomerular C4d deposition. For patient 1, DSA remained below detectable thresholds for 6 months following bortezomib treatment. For patient 2, DSA remained below detectable thresholds for 2 months before a rebound in DSA titers were observed. A repeat cycle of $\mathrm{PP}$, rituximab, and bortezomib treatment was given showing undetectable DSA within the first week of retreatment [19]. The group concluded that bortezomib-based regimens may be beneficial in rapid DSA elimination in the setting of acute AMR as an adjunct to commonly used modalities such as PP.

In the study by Sberro-Soussan et al., the group came to an opposite conclusion of bortezomib efficacy in four patients at least 1 year out from renal transplantation [20]. In these four patients experiencing subacute AMR, no significant decrease in DSA intensity as measured by MFI occurred despite use of PP, IVIG, rituximab, and bortezomib in 150 days of followup. In addition, bortezomib's activity on long-lived plasma cells as measured by observing any decrease in antiviral antibodies (antihepatitis B surface antigen) and total IgG was not demonstrated as neither decreased significantly with a cycle of bortezomib. The group postulated that lack of activity against DSA may have been secondary to a long period of DSA stability following transplant as bortezomib was administered nearly 1 year or more after transplantation of these patients. They concluded that a single cycle of bortezomib does not seem to exert an effect on any long-lived antibody levels (further than 1 year post-transplant) whether the long-lived antibodies be DSA in sensitized kidney transplant recipients, anti-viral antibodies, or total immunoglobulins [20]. Yet, the group postulated that bortezomib may be more effective in more short-lived, intensely producing plasma cells as previously noted in the literature. Finally, as this is the only study to use bortezomib as solo immunotherapy, steroids may be critical for a synergistic, proapoptotic effect in normal plasma cells.

\section{Conclusions}

Bortezomib's ability to target antibody producing plasma cell has generated interest in its use for pre-transplant desensitization and treatment of AMR. This drug may provide a promising insight into the management of patients undergoing kidney transplantation especially considering the large numbers of highly sensitized patients on the kidney transplant waiting list. New therapeutic strategies targeting reduction in DSA as well as managing AMR can provide opportunities for these patients. Although limited experience with bortezomib may seem to show promise in the realm of transplant recipients desensitization and treatment of AMR, there is also experience that may suggest otherwise. Specifically, the use of bortezomib with other accepted modalities for desensitization (PP, IVIG, and rituximab) may make it difficult to tease out bortezomib's role in transplant desensitization and treatment of AMR as highlighted in the limited reported instances of its use. Bortezomib's role in transplant desensitization may be better elucidated as more clinical data and well-designed clinical trials become available.

\section{Authors' Contributions}

A. Jeroudi and R. Raghavan (lead author) contributed equally to the completion of the literature review and the completion of the early drafts of the paper. A. Abdellatif (senior and corresponding author), K. Achkar, and A. O. Gaber edited and completed the final revisions. S. J. Patel is a transplant clinical pharmacist and compiled the data on Bortezomib's pharmacokinetics.

\section{Conflict of Interests}

There is no conflict of interests in this paper.

\section{References}

[1] R. A. Wolfe, V. B. Ashby, E. L. Milford et al., "Comparison of mortality in all patients on dialysis, patients on dialysis awaiting transplantation, and recipients of a first cadaveric 
transplant," New England Journal of Medicine, vol. 341, no. 23, pp. 1725-1730, 1999.

[2] A. A. Vo, A. Peng, M. Toyoda et al., "Use of intravenous immune globulin and rituximab for desensitization of highly HLA-sensitized patients awaiting kidney transplantation," Transplantation, vol. 89, no. 9, pp. 1095-1102, 2010.

[3] R. A. Montgomery, "Renal transplantation across HLA and $\mathrm{ABO}$ antibody barriers: integrating paired donation into desensitization protocols," American Journal of Transplantation, vol. 10, no. 3, pp. 449-457, 2010.

[4] US Renal Data System, "USRDS 2009 Annual Data Report: Atlas of Chronic Kidney Disease and End-Stage Renal Disease in the United States," Chapter 7, page 292, National Institutes of Health, National Institute of Diabetes and Digestive and Kidney Diseases, Bethesda, Md, USA, 2009.

[5] B. L. Kasiske, M. G. Zeier, J. C. Craig et al., "KDIGO clinical practice guideline for the care of kidney transplant recipients," American Journal of Transplantation, vol. 9, supplement 3, pp. S1-S157, 2009.

[6] D. B. Tyan, V. A. Li, L. Czer, A. Trento, and S. C. Jordan, "Intravenous immunoglobulin suppression of HLA alloantibody in highly sensitized transplant candidates and transplantation with a histoincompatible organ," Transplantation, vol. 57, no. 4, pp. 553-562, 1994.

[7] R. A. Montgomery, A. A. Zachary, L. C. Racusen et al., "Plasmapheresis and intravenous immune globulin provides effective rescue therapy for refractory humoral rejection and allows kidneys to be successfully transplanted into crossmatch-positive recipients," Transplantation, vol. 70, no. 6, pp. 887-895, 2000.

[8] M. D. Stegall and J. M. Gloor, "Deciphering antibodymediated rejection: new insights into mechanisms and treatment," Current Opinion in Organ Transplantation, vol. 15, no. 1, pp. 8-10, 2010.

[9] P. I. Terasaki, "Humoral theory of transplantation," American Journal of Transplantation, vol. 3, no. 6, pp. 665-673, 2003.

[10] C. Lefaucheur, D. Nochy, J. Andrade et al., "Comparison of combination plasmapheresis/IVIg/Anti-CD20 versus highdose ivig in the treatment of antibody-mediated rejection," American Journal of Transplantation, vol. 9, no. 5, pp. 1099$1107,2009$.

[11] S. Jordan, C. Cunningham-Rundles, and R. McEwanc, "Utility of intravenous immune globulin in kidney transplantation: efficacy, safety, and cost implications," American Journal of Transplantation, vol. 3, no. 6, pp. 653-664, 2003.

[12] H. E. Adrogue, L. Soltero, G. A. Land, V. Ramanathan, L. D. Truong, and W. N. Suki, "Immunoglobulin therapy for plasma cell-rich rejection in the renal allograft," Transplantation, vol. 82, no. 4, pp. 567-569, 2006.

[13] E. J. Ramos, H. S. Pollinger, M. D. Stegall, J. M. Gloor, A. Dogan, and J. P. Grande, "The effect of desensitization protocols on human splenic B-cell populations in vivo," American Journal of Transplantation, vol. 7, no. 2, pp. 402-407, 2007.

[14] M. J. Everly, J. J. Everly, B. Susskind et al., "Bortezomib provides effective therapy for antibody- and cell-mediated acute rejection," Transplantation, vol. 86, no. 12, pp. 17541761, 2008.

[15] H. L. Trivedi, P. I. Terasaki, A. Feroz et al., "Abrogation of AntiHLA antibodies via proteasome inhibition," Transplantation, vol. 87, no. 10, pp. 1555-1561, 2009.

[16] D. K. Perry, J. M. Burns, H. S. Pollinger et al., "Proteasome inhibition causes apoptosis of normal human plasma cells preventing alloantibody production," American Journal of Transplantation, vol. 9, no. 1, pp. 201-209, 2009.

[17] A. Idica, H. Kaneku, M. J. Everly et al., "Elimination of posttransplant donor-specific HLA antibodies with bortezomib," Clinical transplants, pp. 229-239, 2008.

[18] M. Wahrmann, M. Haidinger, G. F. Körmöczi et al., "Effect of the proteasome inhibitor bortezomib on humoral immunity in two presensitized renal transplant candidates," Transplantation, vol. 89, no. 11, pp. 1385-1390, 2010.

[19] R. C. Walsh, J. J. Everly, P. Brailey et al., "Proteasome inhibitorbased primary therapy for antibody-mediated renal allograft rejection," Transplantation, vol. 89, no. 3, pp. 277-284, 2010.

[20] R. Sberro-Soussan, J. Zuber, C. Suberbielle-Boissel et al., "Bortezomib as the sole post-renal transplantation desensitization agent does not decrease donor-specific anti-HLA antibodies," American Journal of Transplantation, vol. 10, no. 3, pp. 681-686, 2010.

[21] J. F. San Miguel, R. Schlag, N. K. Khuageva et al., "Bortezomib plus melphalan and prednisone for initial treatment of multiple myeloma," New England Journal of Medicine, vol. 359, no. 9, pp. 906-917, 2008.

[22] P. M. Voorhees, E. C. Dees, B. O'Neil, and R. Z. Orlowski, “The proteasome as a target for cancer therapy," Clinical Cancer Research, vol. 9, no. 17, pp. 6316-6325, 2003.

[23] A. Durrbach, H. Francois, S. Beaudreuil, A. Jacquet, and B. Charpentier, "Advances in immunosuppression for renal transplantation," Nature Reviews Nephrology, vol. 6, no. 3, pp. 160-167, 2010.

[24] K. Neubert, S. Meister, K. Moser et al., "The proteasome inhibitor bortezomib depletes plasma cells and protects mice with lupus-like disease from nephritis," Nature Medicine, vol. 14, no. 7, pp. 748-755, 2008.

[25] "Velcade (bortezomib) package insert," Millenium Pharmaceuticals, Cambridge, Mass, USA, 2009.

[26] D. E. Reece, D. Sullivan, S. Lonial et al., "Pharmacokinetic and pharmacodynamic study of two doses of bortezomib in patients with relapsed multiple myeloma," Cancer Chemotherapy and Pharmacology. Epub ahead of print.

[27] K. Venkatakrishnan, M. Rader, R. K. Ramanathan et al., "Effect of the CYP3A inhibitor ketoconazole on the pharmacokinetics and pharmacodynamics of bortezomib in patients with advanced solid tumors: a prospective, multicenter, open-label, randomized, two-way crossover drug-drug interaction study," Clinical Therapeutics, vol. 31, part 2, pp. 2444-2458, 2009.

[28] G. Perrone, T. Hideshima, H. Ikeda et al., "Ascorbic acid inhibits antitumor activity of bortezomib in vivo," Leukemia, vol. 23, no. 9, pp. 1679-1686, 2009.

[29] P. G. Richardson, B. Barlogie, J. Berenson et al., "A phase 2 study of Bortezomib in relapsed, refractory myeloma," New England Journal of Medicine, vol. 348, no. 26, pp. 2609-2617, 2003.

[30] R. C. Walsh, R. Shields, S. Safdar et al., "Toxicity profile of proteasome inhibitor-based antihumoral therapy in renal transplant candidates and recipients," American Journal of Transplantation, vol. 10, supplement 4, p. 171, 2010, abstract.

[31] R. Raghavan, A. Jeroudi, K. Achkar et al., "Bortezomib in kidney transplant desensitization: a case report," Clinical transplants, pp. 339-342, 2009. 


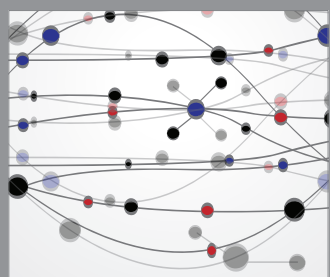

The Scientific World Journal
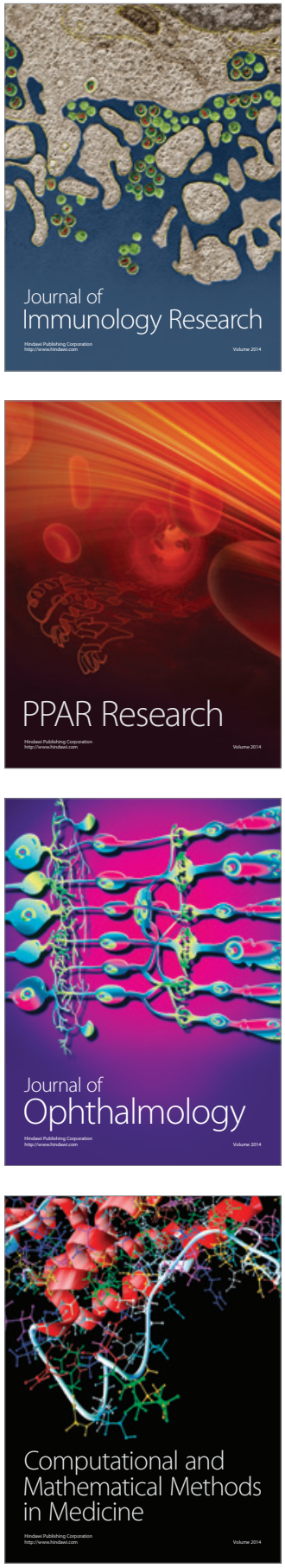

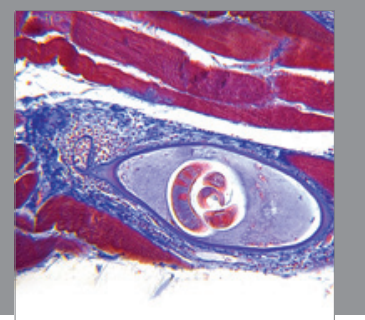

Gastroenterology

Research and Practice
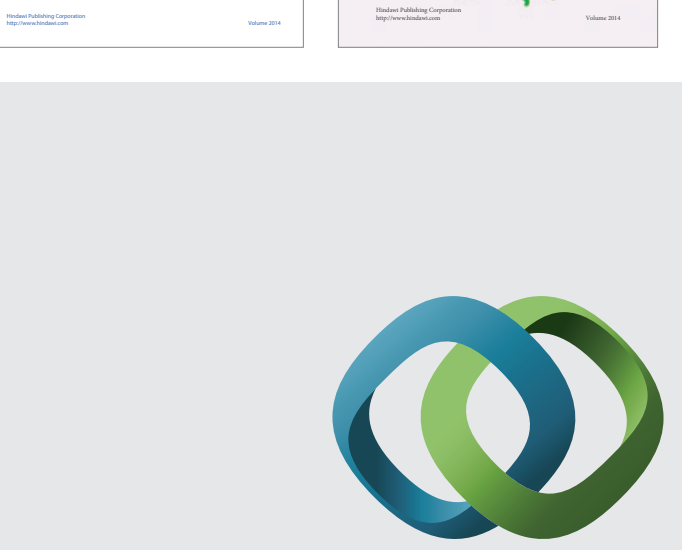

\section{Hindawi}

Submit your manuscripts at

http://www.hindawi.com
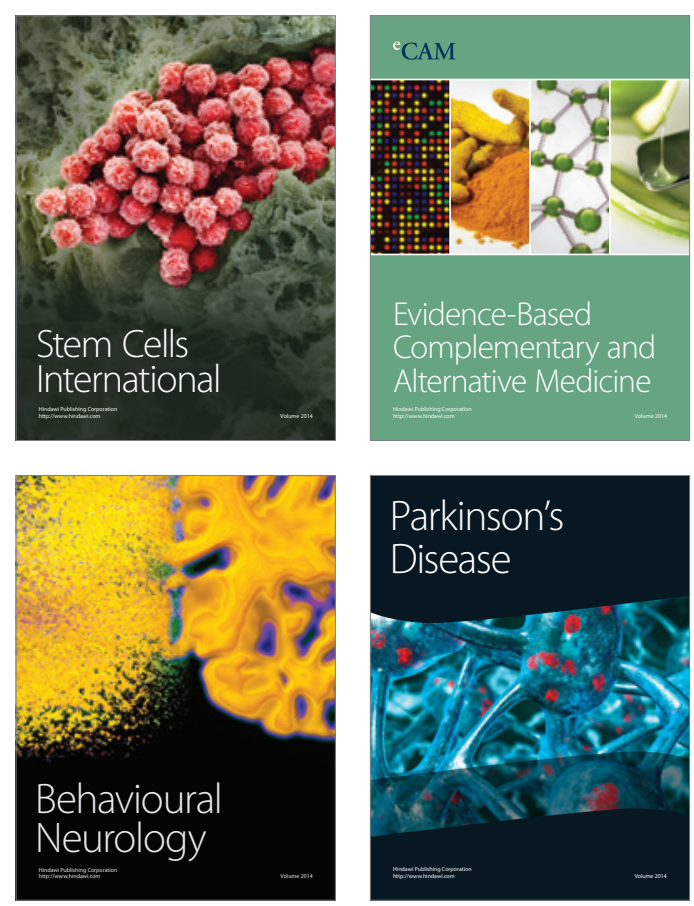

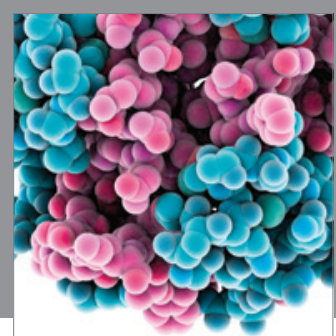

Journal of
Diabetes Research

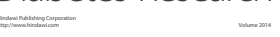

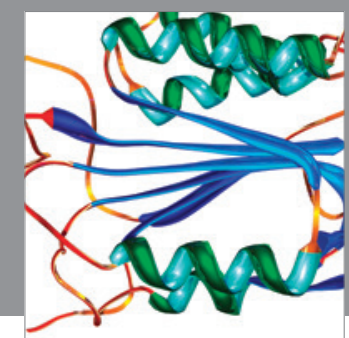

Disease Markers
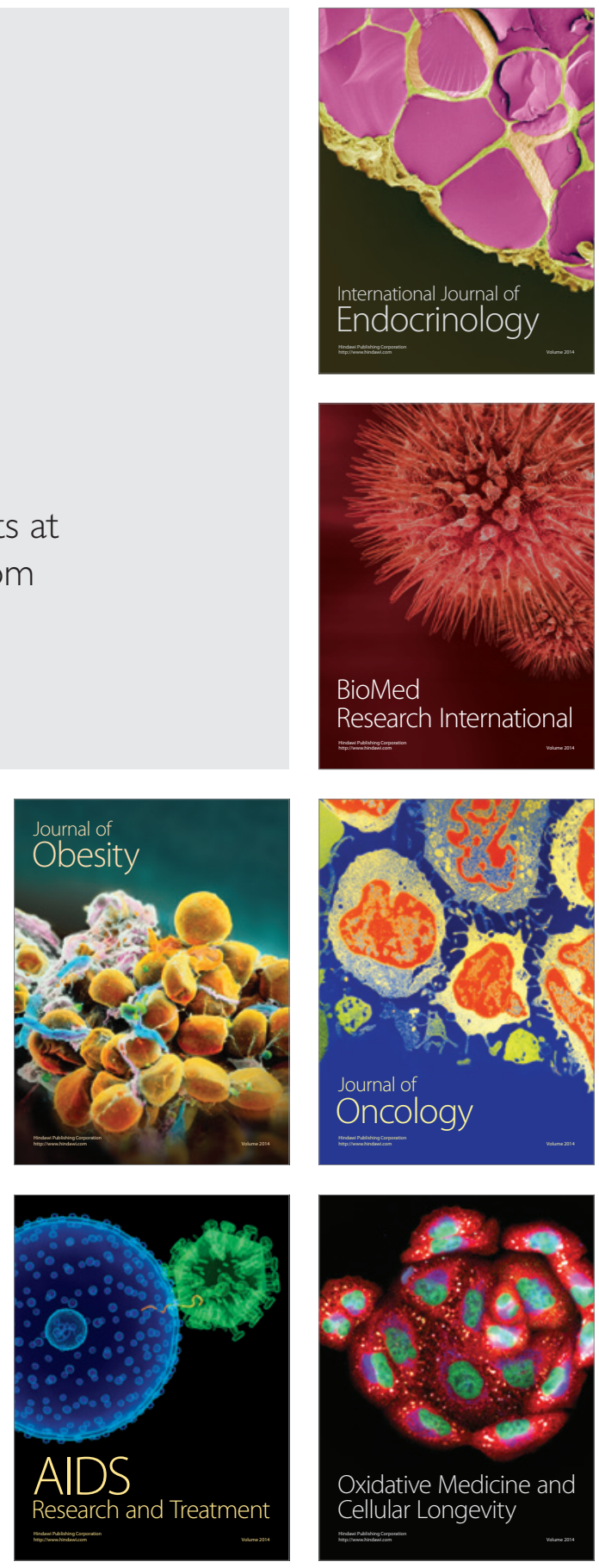